\title{
Whole-body diffusion-weighted MRI versus CT for detection, restaging and operability assessment of recurrent ovarian carcinoma
}

\author{
K Michielsen ${ }^{1 *}$, I Vergote ${ }^{2}$, K Op de beeck ${ }^{1}$, F Amant ${ }^{2}$, K Leunen $^{2}$, S Dymarkowski ${ }^{1}$, P Moerman ${ }^{3}$, F De Keyzer ${ }^{1}$, \\ $\checkmark$ Vandecaveye $^{1}$
}

From International Cancer Imaging Society (ICIS) 14th Annual Teaching Course

Heidelberg, Germany. 9-11 October 2014

\section{Aim}

To evaluate whole body diffusion-weighted MR imaging (WB-DWI MRI) for detection, staging and operability assessment in recurrent ovarian cancer compared with CT.

\section{Methods}

Fifty-one women suspected for recurrent ovarian cancer underwent 3-Tesla WB-DWI/MRI using 2 b-values $\left(\mathrm{b}=0-1000 \mathrm{~s} / \mathrm{mm}^{2}\right), \mathrm{T} 2$ - and contrast $\mathrm{T} 1$-weighted sequences in addition to CT. WB-DWI/MRI and CT were compared for per-patient detection of recurrence, per-site detection of disease extent including peritoneal, serosal, retroperitoneal, periportal and distant metastases and for detecting disease extent according to institutional operability criteria. Imaging findings were correlated with surgical/pathological findings or imaging follow-up for at least 6 months.

\section{Results}

According to the reference standard, recurrence was confirmed in 48/51 patients. WB-DWI MRI showed 94\% accuracy for detecting recurrence, versus $78 \%$ for CT. Per-site analysis showed significantly higher sensitivity of WB-DWI MRI over CT for assessing disease extent of the peritoneum, small bowel and colon mesentery and serosa $(\mathrm{p}<0.000001, \mathrm{p}<0.000001$ and $\mathrm{p}=0.00002$, respectively), retroperitoneal suprarenal lymphadenopathies and periportal lesions (both $\mathrm{p}=0.031$ ). Following institutional operability criteria, WB-DWI/MRI showed better sensitivity for detection of disease extent compromising operability; mesenteric root infiltration $(\mathrm{p}=0.008)$, carcinomatosis of small bowel $(\mathrm{p}=0.002)$ and colon $(\mathrm{p}=0.016)$, high volumetric peritoneal disease load $(\mathrm{p}=0.004)$ and irresectable distant metastases $(\mathrm{p}=0.016)$. WB-DWI MRI correctly predicted complete cytoreduction in $93 \%$ patients undergoing cytoreductive surgery versus $40 \%$ for CT.

\section{Conclusion}

WB-DWI MRI showed higher accuracy compared with $\mathrm{CT}$ for recurrence detection while improving the sensitivity for staging and operability assessment of disease extent. WB-DWI MRI may be most valuable to select patients for surgical resection.

\section{Authors' details \\ ${ }^{1}$ Department of Radiology, Leuven Cancer Institute, University Hospitals Leuven, Leuven, Belgium. ²Department of Obstetrics and Gynaecology, Leuven Cancer Institute, University Hospitals Leuven, Leuven, Belgium. ${ }^{3}$ Department of Pathology, Leuven Cancer Institute, University Hospitals Leuven, Leuven, Belgium.}

Published: 9 October 2014

* Correspondence: katrijn.michielsen@med.kuleuven.be

'Department of Radiology, Leuven Cancer Institute, University Hospitals

Leuven, Leuven, Belgium

Full list of author information is available at the end of the article 